\section{What role for national trees in promoting biodiversity conservation?}

Although some have long understood the need for biodiversity conservation, others are only now coming to an understanding of its importance through today's headlines. We learn daily of new threats to the natural world, of additional species placed on endangered and threatened lists, of entire regions imperiled by the loss of vegetation. But often it remains difficult for people to grasp the relationship between biodiversity loss and their daily lives. Conservation organizations need to help make the links through their public awareness and conservation programmes. Choosing symbols, particularly for the less 'cuddly' species, is a way forward.

Although there are many faces and approaches to conservation, The National Arbor Day Foundation was founded in 1972, the centennial of the tree planters' holiday in the United States (US), to help people plant and care for trees. In this way, they have a direct appreciation and responsibility for the natural world. The Arbor Day Foundation has grown to offer conservation programmes for cities and towns, for farms, fields, and riparian areas, for construction and new housing developments, for utility companies, and for our nation's forests. In addition, through our Rainforest Rescue Program we aim to make people aware of the global threat to rainforests and to highlight the tangible steps that people can take to help prevent this loss.

Today more than 8000 species of trees, or 10 per cent of the world's total, are threatened with extinction. In nearly all countries of the world trees are under threat - the scale of potential loss is truly global. In the US alone over 250 tree species are recorded as threatened with extinction as defined by the IUCN Red List categories, with a concentration of such species in the State of Hawaii. To underscore the value of trees, The Arbor Day Foundation is inviting the US public to help choose a national tree via internet voting. In this way we hope to select a flagship species to help celebrate the value of trees.

In countries around the world, pride in trees is being invoked to involve the public in conservation issues. In the 1980s and 1990s, the people of Finland chose six nature symbols by popular vote, including the birch as national tree. Although the banyan is considered the national tree of India, the World Wide Fund for Nature India has urged that the peepal and neem should also be given official designation because of their importance to the Indian people. Fauna \& Flora International's Soundwood Programme is working with local people to preserve the endangered Pau Brasil and the mpingo, the national trees of Brazil and Tanzania, respectively.

People across the globe have long known the maple as a symbol of Canada, with official status being granted in 1996, whereas Estonians have not formally recognized the oak, they have long held it to be sacred. The oak is similarly prized by the people of Germany and Latvia, although it shares this distinction with the linden in Latvia. In Japan, the sugi pine is revered as a national tree, as it is the real yellow wood in South Africa. In Lebanon, the national tree, the cedar of Lebanon, is a flagship for an effective conservation programme throughout the country.

Many island and tropical countries have designated national trees to reflect their unique cultures. By a popular vote held in 1996, the Cayman Islands selected the silver thatch palm as their national tree. Jamaica named the blue mahoe, and the narra is the national tree of the Philippines. In the Maldives, the coconut palm was given similar recognition in 1985, whereas the 'tree of life', or lignum vitae, has been named the national tree of the Bahama Islands. Antigua and Barbuda selected the whitewood tree, whereas Belize recognizes the mahogany. The government of Costa Rica granted national tree status to the guanacaste on 31 August 1959. Some of these species are threatened with extinction and their selection for national tree status should certainly help to ensure that they are conserved effectively.

As these examples show, national trees are as diverse as the countries they represent, and their distinctness often reflects the vital differences between cultures. Yet the importance of trees transcends national boundaries and concerns. When people choose a national tree, they signal their appreciation and respect for all trees. In that spirit, on 27 April, Arbor Day 2001, The National Arbor Day Foundation will plant the tree selected by the American people, and urge other groups within the country to do the same.

We will then be proud to join those who have already designated or are in the process of naming their own national trees, as a gesture of our dependence on trees for the products and ecological services they provide, for cleaner air and water, richer soil and the promise of a sustainable future. 
John Rosenow, President,

The National Arbor Day Foundation,

100 Arbor Avenue,

Nebraska City, NE 68410,

USA.

e-mail: jrosenow@arborday.org
Visit the Foundation's web site - www.arborday.org for further details of the national tree scheme.

\section{Letter from the editor}

First, I would like to wish all readers a Happy New Year. I hope that 2001 will be a fruitful year for conservation, and that real progress can be made in our efforts to conserve biodiversity. It would be wonderful to be able to report more 'good news' stories in the Briefly section, which so often seems to be dominated by tales of species declines and losses.

The year 2000 was successful for Oryx, with more papers submitted than in any previous year (at the time of writing, 65 papers had been submitted, compared with 56 in the whole of 1999) - this is a trend we are keen to encourage further. Another piece of good news is that Oryx now has an Impact Factor (IF). The IF is a measure of the number of times that peerreviewed papers have been cited elsewhere in the 2 years following publication. Having an IF is important for a journal because it is often used as an indicator of its quality and standing. The IF for Oryx in 1999 (IFs are awarded retrospectively) is 1.133 placing it 43rd out of 88 journals within the ecology category. This is an excellent start for the journal and the editorial team is committed to maintaining and improving the IF in the future.

Of the papers submitted in 1999, around 50 per cent have been published or accepted for publication, and approximately 15 per cent are with authors for revision. Of those published, the average time between submission and publication was 12 months and the average time between submission and acceptance (following revision) for publication was 7.5 months.

In terms of coverage of the areas in which journal submissions are invited, approximately half of the papers published in 2000 presented field research on the status and distribution of threatened species. A small number fell within the following broad categories: review of the status and distribution of individual species or taxonomic groups; planning for species and biodiversity conservation; and the nature and results of practical conservation initiatives by governmental and non-governmental organizations. Most of the remaining papers (around 30 per cent) addressed issues that are not specifically outlined in the scope of the journal, but are nevertheless of relevance to the readership (e.g. effects of human activity on biodiversity, human-wildlife conflict, implications of forest loss and fragmentation for wildlife conservation, and health implications of the rehabilitation of illegally traded species). Underrepresented areas where the editors would be keen to see a wider range of contributions include:

- reviews of conservation policy and legislation at international, national and local levels

- the working of international conservation conventions

- research on the sustainable use of wild species

- the history of conservation, including the role of key people, organizations and initiatives

- planning for species and biodiversity conservation

- results of practical conservation initiatives.

As far as coverage of taxonomic groups is concerned, more than half the papers focus on mammals. A smaller proportion address taxonomic groups such as birds, reptiles, amphibians, plants, trees and insects - there is clearly considerable scope for improving coverage in these areas. In addition, more interdisciplinary papers, including those with a human or social scientific focus would be welcome.

Only one significant change is planned to the structure of Oryx in 2001. A new section, Forum, is to be introduced. Forum aims to promote lively debate about current and controversial issues. Topics for discussion will be identified by the editors, with opposing views being commissioned from two or more authors and then published as short papers (generally $<2000$ words). Occasionally, a submitted paper may be considered suitable for publication in Forum, in which case the author's paper, one or more opposing viewpoints and the author's response will be published in the same issue. The Editors welcome suggestions for suitable Forum topics and contributors.

In addition, the existing Opinion section is to be replaced by a Letters section. Readers are invited to continue to respond to material published in previous issues of the journal.

For further details of the coverage of the journal, outlines of the different sections, and guidelines on the preparation of papers for submission to Oryx, please see the notes for contributors on the inside back cover.

Camilla Erskine 